\title{
Redox reactions in food fermentations
}

\author{
Hansen, Egon Bech
}

Published in:

Current Opinion in Food Science

Link to article, DOI:

10.1016/j.cofs.2018.03.004

Publication date:

2018

Document Version

Peer reviewed version

Link back to DTU Orbit

\section{Citation (APA):}

Hansen, E. B. (2018). Redox reactions in food fermentations. Current Opinion in Food Science, 19, 98-103. https://doi.org/10.1016/j.cofs.2018.03.004

\section{General rights}

Copyright and moral rights for the publications made accessible in the public portal are retained by the authors and/or other copyright owners and it is a condition of accessing publications that users recognise and abide by the legal requirements associated with these rights.

- Users may download and print one copy of any publication from the public portal for the purpose of private study or research.

- You may not further distribute the material or use it for any profit-making activity or commercial gain

- You may freely distribute the URL identifying the publication in the public portal

If you believe that this document breaches copyright please contact us providing details, and we will remove access to the work immediately and investigate your claim. 


\section{Accepted Manuscript}

Title: Redox reactions in food fermentations

Author: Egon Bech Hansen

PII:

DOI:

S2214-7993(17)30103-0

Reference: https://doi.org/doi:10.1016/j.cofs.2018.03.004

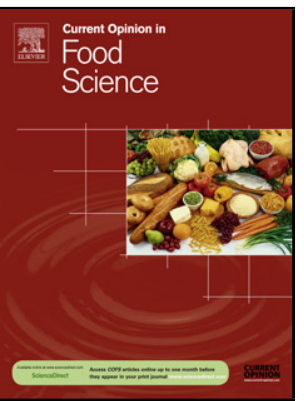
COFS 345

To appear in:

Received date: 15-11-2017

Revised date: 27-2-2018

Accepted date: 3-3-2018

Please cite this article as: Hansen, E.B.,Redox reactions in food fermentations, COFS (2018), https://doi.org/10.1016/j.cofs.2018.03.004

This is a PDF file of an unedited manuscript that has been accepted for publication. As a service to our customers we are providing this early version of the manuscript. The manuscript will undergo copyediting, typesetting, and review of the resulting proof before it is published in its final form. Please note that during the production process errors may be discovered which could affect the content, and all legal disclaimers that apply to the journal pertain. 
1 Redox reactions in food fermentations

2

3

4 Egon Bech Hansen

5

6

7

8 National Food Institute

9 Technical University of Denmark

10 Kemitorvet bldg.. 202

11 DK2800 Kgs. Lyngby

12 Denmark

13 Phone: +4535886203

14 e-mail: egbh@food.dtu.dk

15 


\section{Abstract}

17 Food fermentations are typically performed without actively supplying air. Except for possible surface microorganisms, oxygen will only be transiently available and the redox reactions during the fermentation need to be in balance. Production of ATP from fermentation of carbohydrates typically involves oxidative steps in the early part of the pathways whereas a multitude of different reactions are used as compensating reductions. Much of the diversity seen between food fermentations arise from the different routes and the different electron acceptors used by microorganisms to counterbalance the initial oxidative steps. This review gives a short overview of the routes employed by microorganisms in food fermentations to find ultimate electron acceptors allowing them to balance their fermentative metabolism.

25 The diversity of acceptors used leads to diversity of metabolic end products and this contributes to the diversity in flavor, color, texture, and shelf life. The review concludes that these reactions are still only incompletely understood and that they represent an interesting area for fundamental research and also represent a fertile field for product development through a more conscious use of the redox properties of strains used to compose food cultures. 
Introduction

Fermented foods have during centuries been produced without any knowledge of microbiology and even today

our knowledge of the beneficial microorganisms is still quite limited. More than 200 species of microorganisms have a documented history of use in food fermentations [1] and a handful of those are produced and made available as commercial starter cultures [2]. Fermented food spans a large range of products with the major categories being: alcoholic beverages (beer and wine); fermented doughs; vinegar; fermented dairy products (cheese, yoghurt, and fermented milks); fermented soy (miso, tempeh, natto, and soy sauce); fermented fish; fermented meat; fermented coffee; and fermented cocoa [1]. Sensu stricto fermentation was defined as life without air as opposed to respiration. However, the above list of microorganisms in fermented foods is based on a less strict definition and include some aerobic microbial processes like production of vinegar and surface ripening of cheese and sausages. Nevertheless, the majority of food fermentations are performed with no supply of air.

It might seem surprising that imposing a limitation on the microbial metabolism by withholding air should lead to an increased diversity of flavors and textures produced by the cultures. In comparison to a respiratory metabolism which mainly produce $\mathrm{CO}_{2}$ and water as end products, the anaerobic metabolisms give a wide range of end products as ethanol, acetoin, diacetyl, acetaldehyde, lactic acid, acetic acid, and other acids in addition to water and $\mathrm{CO}_{2}[3]$.

Redox reactions are chemical reactions involving the transfer of electrons between molecules where the donor molecule is said to be oxidized and the recipient reduced. Although the two reactions must be simultaneous, they can, in a galvanic cell, be separated to occur at different electrodes. For each reaction, the standard potential $E^{0}$ (measured in volts, $V$ ) defines the condition where electrons are gained or lost at equal rates. The 
53 value of $E_{h}$ relative to $E^{0}$ will determine the tendency for a molecule to receive or donate electrons (to oxidize 54 or to be oxidized). Lactic acid bacteria (LAB) play a prominent role in food fermentations with respect to volume, diversity of raw materials, and diversity of species. Traditionally the primary performance parameter for starter cultures for the food industry has been the acidification activity. The second parameter has been robustness towards phage infections, which is another manifestation of reliability of acidification [2]. Texture and taste have been of lower priority and for this reason less attention has been given to $\mathrm{E}_{\mathrm{h}}$ compared to $\mathrm{pH}$.

This review focus on redox reactions in LAB and the conclusion will be that innovation in food fermentations can be dramatically stimulated with increased knowledge on redox reactions when composing the starter cultures for food fermentation.

Fermentation

The fermentative metabolism is most easily understood by separating energy production from maintenance of redox homeostasis. Off course in reality, this is not possible.

ATP is typically generated from metabolizing carbohydrates into pyruvate by oxidation. Different pathways to pyruvate can be used depending on the organism and the sugar. Glycolysis by the Embden-Meyerhof-Parnas pathway is a main route but the so-called hetero-fermentative pathways involving phosphoketolase enzymes in key metabolic steps are also quite common [3]. The net gain of ATP differs between the pathways and the ATP yield depends on the uptake mechanism and the length of the carbohydrate. Gänsle has recently reviewed the main carbohydrate metabolisms of LAB [5]. The oxidation of carbohydrates to pyruvate consumes NAD in addition to the production of ATP, and this redox-debt must be paid back. An additional reward in the form of gaining extra ATP by shifting from ethanol to acetate production is available for the hetero-fermentative LAB if they can mobilize extra NAD generating capacity [6-8]. 
Regeneration of NAD is accomplished by the concerted action of all cellular oxidoreductases. However, only

the ones having an available electron acceptor will contribute under any given condition. We have probably only identified the most obvious electron acceptors as we tend to reduce complexity when we study microbial metabolism. The discovery of relevant electron acceptors utilized during food fermentations will require the researcher to use the relevant food as medium in the research.

Pyruvate is the primary electron acceptor for LAB. This is in fact what unifies the group of lactic acid bacteria, they produce lactic acid as the major end product. Pyruvate is reduced to lactate by the enzyme lactate dehydrogenase (LDH) with concomitant oxidation of NADH to NAD [3]. Homo-fermentative LAB relay mainly on pyruvate and LDH for NAD regeneration [9]. NAD regeneration solely by LDH leaves very little flexibility in the metabolic network and LAB will therefore benefit by having alternative routes to NAD regeneration and even homo-fermentative LAB will usually possess alternative routes to regenerate NAD [10].

$\underline{\text { Oxygen, } \mathrm{O}_{2}}$, offers, if present, such an alternative to regenerate NAD by oxidizing NADH via the NADH oxidases, NoxE or NoxAB [11-13]. Some LAB even have a rudimentary electron transport chain including cytochromes $[11,14-16]$. Traditionally most LAB have been considered to be anaerobic and much research has been devoted to study the relationship between LAB and oxygen from the angle of oxidative stress [12,17-19]. It was quite a surprise when Duwatt et al in 2001 showed that Lactococcus is able to respire if hemin is supplied in the medium [15]. It now seems clear that the LAB ancestors were aerobes and that the ability to respire has since been lost to various degrees as a consequence of genome reduction in the course of specialization to the nutrient rich ecological niches where LAB are commonly found [20-22]. In the light of this ancestry it is not surprising that $L A B$ are able to use oxygen when available and that they possess the functions allowing them to deal with aerobic stress. It might therefore be fruitful to look at the redox reactions from the angle of regeneration of NAD rather than aerobic stress management. In a nutrient rich environment, speed might be more important than economy and oxygen might anyhow be the first "nutrient" to be depleted. By losing the 
ability to use the entire chain of oxidative phosphorylation, LAB will use oxygen less efficiently and consume more oxygen and thereby deplete oxygen faster. Rapid consumption of oxygen by LAB might confer an advantage over aerobic bacteria, with which they are commonly in competition in food matrices. By reorienting the metabolic pathways towards the use of additional electron acceptors, LAB might have become better adapted to efficiently remove air and to live well without it. The diversity of the routes developed by LAB to use alternative electron acceptors are illustrated in Figure 1 and several of the electron acceptors used by some LAB are listed in Table 1 and described further in the following sections. However, an increased focus on the positive aspects of oxygen in NAD regeneration should not lead to a neglect of the negative aspects of reactive oxygen species.

\section{Alternative electron acceptors}

One way to gain more flexibility is to acquire pyruvate with no "NAD-debt" and this is the main benefit of utilizing citrate. Several LAB are metabolizing citrate without generating ATP from the citrate to pyruvate pathway [23] . However, as no NAD has been consumed, the pyruvate from citrate can be used with greater flexibility than pyruvate from sugar metabolism. It can be reduced to lactate with concomitant NAD production, or the pyruvate can be directed towards other products than lactate including ATP-generating routes [23].

Sugars can be used as electron acceptors by several fermentative LAB leading to the production of sugar alcohols as mannitol and erythritol [24-26]. Similarly, fumarate and malate can serve as electron acceptors and be reduced to succinate [27].

Phenolics, which are frequently found in fruits, are generally antimicrobial but some LAB use phenolics as electron acceptors; their growth are stimulated by phenolics and the ratio of fermentation end products is altered $[28,29]$. Similarly, LAB able to use other molecules for NAD regeneration can probably be isolated from 
122

123

124

125

126

127

128

129

130

131

132

134

135

136

137

138

139

140

141

142

143

144

nature or constructed by engineering to make LAB become a general tool for reductions in bio-refinery processes [30].

\section{Inside or outside}

The location of the electron acceptor molecule would seem of minor importance as long as NAD is

regenerated. However, it is energetically favorable to keep the negatively charged electrons inside the cell and the positively charged protons outside of the cell membrane [31]. If the electron acceptor is uncharged and able to diffuse through the membrane, reducing on the inside is likely to be more favorable. Oxygen, $\mathrm{O}_{2}$, can be reduced on the outside of the cell to $\mathrm{O}_{2}^{-}$by direct reduction via menaquinones or reduced on the inside by NoxE or NoxAB and cytochrome bc [32,33]. The cytochrome reaction is the most efficient as charge is separated by releasing protons on the outside while reducing $\mathrm{O}_{2}$ on the inside [20]. Fructose is another example of a molecule, which can be imported for the purpose of being reduced to mannitol and then again exported [27].

The bacterial membrane serves as the barrier over which a $\mathrm{pH}$ and charge difference builds an electrochemical gradient able to drive transport and ATP production. In addition to carrying the energy potential, the membrane also serves as a reservoir and buffer for redox-equivalents [34].

\section{Redox reactions on the membrane and cell wall}

Menaquinones and menaquinols serve as carriers of reducing equivalents between oxidoreductases located in the membrane [34]. They constitute an important component in the electron transport chain in oxidative phosphorylation; other components of the respiratory process are cytochrome-bd and NoxAB $[16,22,35-38]$.

Due to the link to the respiratory pathway, research has focused on understanding the role of menaquinones in oxygen metabolism and relief of oxidative stress. The role of menaquinones in the anaerobic metabolism has 
145 been somewhat out of focus although it has been recognized that lactococci produce menaquinones in anaerobic growth [39] and that the production is twofold higher during anaerobic conditions compared to aerobic growth [16]. The experiments of Tachon, Brandsma, and Yvon [11] demonstrated that during fermentation in milk rapid removal of oxygen by Lactococcus lactis is mainly accomplished by the NoxE enzyme whereas menaquinones and NoxAB are responsible for maintaining the low redox potential during the stationary (anaerobic) phase. The same authors also demonstrated that in Lactococcus menaquinones are participating in redox reactions on either face of the bacterial membrane and that NoxAB can use other electron acceptors than menaquinones [11]. This seems to indicate that lactococci mainly utilize menaquinones and NoxAB when air is absent or scarce.

Menaquinones might be a vehicle to use extracellular electron acceptors as direct reduction of tetrazolium salts and metal ions have been demonstrated [11,32]. Using an extracellular electron acceptor would appear to be less favorable than using an intracellular one as export of an electron will reduce the electrochemical gradient over the membrane. One would therefore expect that this option should be reserved for molecules which cannot be imported or which are unfavorable to import. It is unclear if this route contributes to NAD regeneration under fermentation of milk. If it does, the terminal electron acceptors in milk remain to be determined. Lab species commonly used in dairy fermentations differ widely in their ability to lower the redox potential during fermentation [40]. Also strains within the same species show large difference [11,41]. of electrons between different oxidoreductases. In the oxidized form, two cysteines are bridged covalently via the sulfur atoms; whereas the sulfur atoms will be free thiol groups in the reduced form. The two cysteines can be in the same polypeptide chain as in thioredoxin, or located on different molecules, or, as in glutathione, between two identical molecules. Thioredoxin and glutathione participate in a variety of redox reactions involving the formation and breakage of disulfide bridges [42]. The sulfur redox reactions are coupled to the 
NAD/NADH catalyzed redox reactions through the enzymes thioredoxin reductase and glutathione reductase.

Neither thioredoxin nor glutathione are essential for Lactococcus lactis [43]. The maintenance of components

of the thioredoxin and gluthathione systems without being essential could point towards a function in the

transport of electrons allowing efficient regeneration of NAD, i.e. to transport electrons towards an electron

acceptor. Michelon et al showed that the very low redox potential reached by Lactococcus lactis in MRS

medium is due to exofacial thiol groups of membrane proteins maintained in the reduced state [44]. The

authors found that only the exofacial thiol groups contributed to the low redox potential and that reduction of

media components did not contribute [44]. It is difficult to understand why such a system would be maintained

in the course of evolution if the only outcome would be a dead end for the electrons in the form of reduced

thiol groups at the surface of the cell. It would make more sense if the reduced thiol represented a channel through which the electrons can flow towards an ultimate acceptor. Obviously, the MRS medium used did not contain such an acceptor. If the dairy associated Lactococcus lactis strains have evolved to perform optimally in milk, one would assume that milk would contain a final acceptor for electrons transferred via the exofacial thiol groups. Milk proteins would seem to be the most likely candidates. Titration of free thiol groups during milk fermentation could possibly reveal if milk contrary to MRS can serve as electron acceptor. To date, this analysis has not been conducted yet. Interestingly the analysis for free thiol groups have been done during sourdough fermentation and gave a clear difference. Sourdoughs fermented by Lactobacilli show a difference of 3-5 mM of free thiol groups compared to chemically acidified doughs [45]. Interesting strategies to identify the exofacial thiol groups in Lactococcus lactis have recently been described by C. Roussel [46].

\section{Perspectives for innovation on fermented food products through redox engineering}

A shift in focus from acidification activity towards diversity of food products could be released through a better 
191 LAB was used to increase the yield of the acidification activity without changing the actual food fermentation

192 [37]. It is, however, surprising that this shift in paradigm has not yet let to a creative use of air and other 193 electron acceptors in food fermentations.

194 In the applied field, it seems obvious to combine strains with different reducing potential to compose cultures

195 with new and improved properties regarding shelf life and flavor. An approach so far mainly used for sour 196 dough cultures [47] but likely to be productive for all food cultures including cultures for dairy. A wider use of $197 E_{h}$ measurement as a control parameter in food fermentations might also be useful as texture and taste have 198 been demonstrated to vary depending on the reduction potential $[48,49]$.

199 Fundamental research on the transport of electrons over the membrane and on expanding the range of identified electron acceptors in food products used for fermentation would seem worthwhile. It is surprising

201 that we do not know which milk molecules are used by Lactococcus lactis to reach the typical low redox potential. It would be interesting to know if the disulfides of milk proteins serve as electron acceptors and to investigate if there is a link to the proteolytic systems of dairy adapted LAB. 
Table 1.

Molecules used as alternative electron acceptors by lactic acid bacteria

\begin{tabular}{|c|c|c|c|}
\hline $\begin{array}{l}\text { electron } \\
\text { acceptor }\end{array}$ & reduced molecule & organism & reference \\
\hline fructose & mannitol & $\begin{array}{l}\text { Lactobacillus sanfranciscensis, } \\
\text { Lactobacillus pontis, } \\
\text { Lactobacillus fermentum, } \\
\text { Lactobacillus florum, } \\
\text { Leuconostoc citreum, } \\
\text { Leuconostoc pseudomesenteroides, } \\
\text { Oenococcus oeni, } \\
\text { Weissella paramesenteroides }\end{array}$ & {$[25,27,50]$} \\
\hline citrate & lactate & $\begin{array}{l}\text { Leuconostocs, Lactobacilli, Weissella, } \\
\text { Lactococcus lactis subsp. } \\
\text { diacetylactis }\end{array}$ & {$[23,27,51]$} \\
\hline fumarate & succinate & $\begin{array}{l}\text { Lactobacillus pontis, } \\
\text { Lactobacillus reuteri, } \\
\text { Lactobacillus amylovorus, } \\
\text { Lactobacillus fermentum }\end{array}$ & {$[27]$} \\
\hline malate & succinate & $\begin{array}{l}\text { Lactobacillus pontis, } \\
\text { Lactobacillus reuteri, } \\
\text { Lactobacillus amylovorus, } \\
\text { Lactobacillus fermentum }\end{array}$ & [27] \\
\hline $\begin{array}{l}\text { glucose, } \\
\text { fructose }\end{array}$ & erythritol & $\begin{array}{l}\text { Lactobacillus sanfranciscensis, } \\
\text { Oenococcus kitaharae, } \\
\text { Oenococcus oeni }\end{array}$ & {$[26,27,50]$} \\
\hline$\alpha$-ketoglutarate & 2-hydroxyglutarate & $\begin{array}{l}\text { Lactobacillus sanfranciscensis, } \\
\text { Lactobacillus reuteri }\end{array}$ & {$[52]$} \\
\hline disulphides & thiols & Lactobacillus sanfranciscensis, & {$[45]$} \\
\hline
\end{tabular}




\begin{tabular}{|l|l|l|l|}
\hline phenolics: & dihydrocaffeic acid & Lactobacillus plantarum & [28] \\
caffeic acid & phloretic acid & Weissella cibaria & \\
p-coumaric acid & dihydroferulic acid & Weissella confuse & \\
ferulic acid & ethylcatechol & Lactobacillus brevis & \\
& ethylphenol & Lactobacillus curvatus & \\
& ethylguaiacol & Lactobacillus rossiae & \\
\hline
\end{tabular}


Bibliography

1. Bourdichon F, Casaregola S, Farrokh C, Frisvad JC, Gerds ML, Hammes WP, Harnett J, Huys G, Laulund S, Ouwehand A, et al.: Food fermentations: Microorganisms with technological beneficial use. Int J Food Microbiol 2012, 154:87-97.

2. Hansen EB: Starter Cultures: Uses in the Food Industry. In Edited by Batt CA, Tortorello ML. Elsevier Ltd, Academic Press,; 2014:529-534.

3. Caplice E, Fitzgerald GF: Food fermentations: Role of microorganisms in food production and preservation. Int J Food Microbiol 1999, 50:131-149.

4. Abraham S, Cachon R, Jeanson S, Ebel B, Michelon D, Aubert C, Rojas C, Feron G, Beuvier E, Gervais P, et al.: A procedure for reproducible measurement of redox potential ( $\mathrm{h}$ ) in dairy processes. Dairy Sci Technol 2013, 93:675-690.

5. Gänzle MG: Lactic metabolism revisited: Metabolism of lactic acid bacteria in food fermentations and food spoilage. Curr Opin Food Sci 2015, 2:106-117.

6. Vedamuthu ER: The Dairy Leuconostoc: Use in Dairy Products. J Dairy Sci 1994, 77:2725-2737.

7. Condon S: Responses of lactic acid bacteria to oxygen. FEMS Microbiol Lett 1987, 46:269-280.

8. Ravyts F, Vuyst L De, Leroy F: Bacterial diversity and functionalities in food fermentations. Eng Life Sci 2012, 12:356-367.

9. Henriksen CM, Nilsson D: Redirection of pyruvate catabolism in Lactococcus lactis by selection of mutants with additional growth requirements. Appl Microbiol Biotechnol 2001, 56:767-775.

10. de Felipe FL, Kleerebezem M, Vos WM de, Hugenholtz J: Cofactor Engineering: a Novel Approach to Metabolic Engineering in Lactococcus lactis by Controlled Expression of NADH Oxidase. J Bacteriol 1998, 180:3804-3808.

11. Tachon S, Brandsma JB, Yvon M: NoxE NADH Oxidase and the Electron Transport Chain Are Responsible for the Ability of Lactococcus lactis To Decrease the Redox Potential of Milk. Appl Environ Microbiol 2010, 76:1311-1319.

12. Higuchi M, Yamamoto Y, Poole LB, Shimada M, Sato Y, Takahashi N, Kamio Y: Functions of Two Types of NADH Oxidases in Energy Metabolism and Oxidative Stress of Streptococcus mutans. J Bacteriol 1999, 181:5940-5947.

13. de Felipe FL, Starrenburg MJC, Hugenholtz J: The role of NADH-oxidation in acetoin and diacetyl production from glucose in Lactococcus lactis subsp. lactis MG1363. FEMS Microbiol Lett 1997, 156:1519.

14. Bolotin A, Wincker P, Mauger S, Jaillon O, Malarme K, Weissenbach J, Ehrlich SD, Sorokin A: The complete genome sequence of the lactic acid bacterium Lactococcus lactis ssp. lactis IL1403. Genome Res 2001, 11:731-53.

15. Duwat $P$, Sourice $S$, Cesselin $B$, Lamberet $G$, Vido $K$, Gaudu $P$, Loir $Y$ Le, Violet $F$, Loubière $P$, Gruss A: Respiration Capacity of the Fermenting BacteriumLactococcus lactis and Its Positive Effects on Growth and Survival. J Bacteriol 2001, 183:4509-4516.

16. Brooijmans R, Smit B, Santos F, van Riel J, de Vos WM, Hugenholtz J: Heme and menaquinone induced electron transport in lactic acid bacteria. Microb Cell Fact 2009, 8:28.

17. Rezaïki L, Cesselin B, Yamamoto Y, Vido K, Van West E, Gaudu P, Gruss A: Respiration metabolism reduces oxidative and acid stress to improve long-term survival of Lactococcus lactis. Mol Microbiol 2004, 53:1331-1342.

18. Efler P, Kilstrup M, Johnsen S, Svensson B, Hägglund P: Two Lactococcus lactis thioredoxin paralogues play different roles in responses to arsenate and oxidative stress. Microbiology 2015, 161:528-538. 
19. Chen J, Shen J, Solem C, Jensen PR: Oxidative stress at high temperatures in Lactococcus lactis due to an insufficient supply of Riboflavin. Appl Environ Microbiol 2013, 79:6140-7.

20. Brooijmans RJW, Poolman B, Schuurman-Wolters GK, Vos WM de, Hugenholtz J: Generation of a Membrane Potential by Lactococcus lactis through Aerobic Electron Transport. J Bacteriol 2007, 189:5203-5209.

21. Makarova K, Slesarev A, Wolf Y, Sorokin A, Mirkin B, Koonin E, Pavlov A, Pavlova N, Karamychev V, Polouchine N, et al.: Comparative Genomics of the Lactic Acid Bacteria. Proc Natl Acad Sci 2006, 103:15611-15616.

22. Pedersen MB, Gaudu P, Lechardeur D, Petit M-A, Gruss A: Aerobic Respiration Metabolism in Lactic Acid Bacteria and Uses in Biotechnology. Annu Rev Food Sci Technol 2012, 3:37-58.

23. Hugenholtz J: Citrate metabolism in lactic acid bacteria. FEMS Microbiol Rev 1993, 12:165-178.

24. Ortiz ME, Bleckwedel J, Raya RR, Mozzi F: Biotechnological and in situ food production of polyols by lactic acid bacteria. Appl Microbiol Biotechnol 2013, 97:4713-4726.

25. Wisselink H., Weusthuis R., Eggink G, Hugenholtz J, Grobben G.: Mannitol production by lactic acid bacteria: a review. Int Dairy J 2002, 12:151-161.

26. Veiga-da-Cunha $\mathrm{M}$, Santos $\mathrm{H}$, Van Schaftingen $\mathrm{E}$ : Pathway and regulation of erythritol formation in Leuconostoc oenos. J Bacteriol 1993, 175:3941-8.

27. Stolz P, Vogel RF, Hammes WP: Utilization of electron acceptors by lactobacilli isolated from sourdough - II. Lactobacillus pontis, L. reuteri, L. amylovorus, and L. fermentum. Z Lebensm Unters Forsch 1995, 201:402-410.

28. Filannino $\mathrm{P}$, Gobbetti M, De Angelis M, Di Cagno R: Hydroxycinnamic acids used as external acceptors of electrons: An energetic advantage for strictly heterofermentative lactic acid bacteria. Appl Environ Microbiol 2014, 80:7574-7582.

29. Rodríguez H, Curiel JA, Landete JM, de las Rivas B, de Felipe FL, Gómez-Cordovés C, Mancheño JM, Muñoz R: Food phenolics and lactic acid bacteria. Int J Food Microbiol 2009, 132:79-90.

30. Sauer M, Russmayer H, Grabherr R, Peterbauer CK, Marx H: The Efficient Clade: Lactic Acid Bacteria for Industrial Chemical Production. Trends Biotechnol 2017, 35:756-769.

31. Unden G, Bongaerts J: Alternative respiratory pathways of Escherichia coli: Energetics and transcriptional regulation in response to electron acceptors. Biochim Biophys Acta-Bioenerg 1997, 1320:217-234.

32. Tachon S, Michelon D, Chambellon E, Cantonnet M, Mezange C, Henno L, Cachon R, Yvon M: Experimental conditions affect the site of tetrazolium violet reduction in the electron transport chain of Lactococcus lactis. Microbiology 2009, 155:2941-2948.

33. Michelon D, Tachon S, Ebel B, De Coninck J, Feron G, Gervais P, Yvon M, Cachon R: Screening of lactic acid bacteria for reducing power using a tetrazolium salt reduction method on milk agar. $J$ Biosci Bioeng 2013, 115:229-32.

34. LeBlanc JG, Milani C, de Giori GS, Sesma F, van Sinderen D, Ventura M: Bacteria as vitamin suppliers to their host: a gut microbiota perspective. Curr Opin Biotechnol 2013, 24:160-168.

35. Lechardeur D, Cesselin B, Fernandez A, Lamberet G, Garrigues C, Pedersen M, Gaudu P, Gruss A: Using heme as an energy boost for lactic acid bacteria. Curr Opin Biotechnol 2011, 22:143-149.

36. Vido K, Bars D le, Mistou M-Y, Anglade P, Gruss A, Gaudu P: Proteome Analyses of Heme-Dependent Respiration in Lactococcus lactis: Involvement of the Proteolytic System. J Bacteriol 2004, 186:16481657.

37. Pedersen MB, Garrigues C, Tuphile K, Brun C, Vido K, Bennedsen M, Møllgaard H, Gaudu P, Gruss A: Impact of Aeration and Heme-Activated Respiration on Lactococcus lactis Gene Expression: Identification of a Heme-Responsive Operon. J Bacteriol 2008, 190:4903-4911. 
38. Guidone A, lanniello RG, Ricciardi A, Zotta T, Parente E: Aerobic metabolism and oxidative stress tolerance in the Lactobacillus plantarum group. World J Microbiol Biotechnol 2013, 29:1713-1722.

39. Morishita T: Production of menaquinones by lactic acid bacteria. J Dairy Sci 1999, 82:1897-1903.

40. Brasca M, Morandi S, Lodi R, Tamburini A: Redox potential to discriminate among species of lactic acid bacteria. J App/ Microbiol 2007, 103:1516-1524.

41. Larsen N, Moslehi-Jenabian S, Werner BB, Jensen ML, Garrigues C, Vogensen FK, Jespersen L: Transcriptome analysis of Lactococcus lactis subsp. lactis during milk acidification as affected by dissolved oxygen and the redox potential. Int J Food Microbiol 2016, 226:5-12.

42. Sevier CS, Kaiser CA: Formation and transfer of disulphide bonds in living cells. Nat Rev Mol Cell Biol 2002, 3:836-847.

43. Li Y, Hugenholtz J, Abee T, Molenaar D: Glutathione protects Lactococcus lactis against oxidative stress. Appl Environ Microbiol 2003, 69:5739-45.

44. Michelon D, Abraham S, Ebel B, De Coninck J, Husson F, Feron G, Gervais P, Cachon R: Contribution of exofacial thiol groups in the reducing activity of Lactococcus lactis. FEBS J 2010, 277:2282-2290.

45. Jänsch A, Korakli M, Vogel RF, Gänzle MG: Glutathione reductase from Lactobacillus sanfranciscensis DSM20451 T: Contribution to oxygen tolerance and thiol exchange reactions in wheat sourdoughs. Appl Environ Microbiol 2007, 73:4469-4476.

46. Roussel C: Compréhension des mécanismes physiologiques et génétiques impliqués dans l'activité réductrice de Lactococcus lactis. These PhD, Université de Bourgogne, Dijon, France; 2015.

47. Capuani A, Werner S, Behr J, Vogel RF: Effect of controlled extracellular oxidation-reduction potential on microbial metabolism and proteolysis in buckwheat sourdough. Eur Food Res Technol 2014, 238:425-434.

48. Kieronczyk A, Cachon R, Feron G, Yvon M: Addition of oxidizing or reducing agents to the reaction medium influences amino acid conversion to aroma compounds by Lactococcus lactis. $J$ Appl Microbiol 2006, 101:1114-22.

49. Abraham S, Cachon R, Colas B, Feron G, De Coninck J: Eh and pH gradients in Camembert cheese during ripening: Measurements using microelectrodes and correlations with texture. Int Dairy J 2007, 17:954-960.

50. Tyler CA, Kopit L, Doyle C, Yu AO, Hugenholtz J, Marco ML: Polyol production during heterofermentative growth of the plant isolate Lactobacillus florum 2F. J Appl Microbio/ 2016, 120:1336-1345.

51. Drider D, Bekal S, Prevost $\mathrm{H}$ : Genetic organization and expression of citrate permease in lactic acid bacteria. Genet Mol Res 2004, 3:273-281.

52. Zhang C, Gänzle MG: Metabolic pathway of $\alpha$-ketoglutarate in Lactobacillus sanfranciscensis and Lactobacillus reuteri during sourdough fermentation. J Appl Microbiol 2010, 109:1301-1310.

\section{Annotation to references}

7. This review by Seamus Condon from 1987 gives an excellent overview of the effect of oxygen on the metabolism of lactic acid bacteria. Although the ability to respire was not known at the time, the review describes the beneficial effect of oxygen on some $L A B$, as well as the oxidative stress.

11. This paper by Tachon et al. from 2010 describes a thorough genetic and physiological analysis of enzymes and cofactors responsible for oxygen removal and lowering of the redox potential of Lactococcus lactis in milk. This paper will become a key paper in the field of LAB metabolism. 
15. Duwat et al. demonstrates in this paper from 2001 with excellent clarity that Lactococcus lactis is able to respire. This paper opens a new scientific field on aerobic respiration in LAB.

31. With simple means Tachon et al. showed that redox reactions take place at both sides of the bacterial membrane.

40. Brasca, Morandi, and Tamburini describes the typical evolution of the redox potential during fermentation in milk by 88 strains from 10 different species. It is surprising that such reference data set is established as late as 2007 . It is also remarkable how different commonly used acidifying LAB behave regarding the final redox potential reached.

44. Michelon et al. 2010 demonstrates clearly that the low redox potential reached by Lactococcus lactis is due to exofacial thiol groups. However, the proteins carrying the thiol groups and the biological function of the thiol groups are not identified. 
Figure legends

Figure 1

Reactions contributing to maintaining redox homeostasis in lactic acid bacteria during fermentative growth $[11,32,44,46]$.

Lactate dehydrogenase (LDH) is the primary electron acceptor for homo-fermentative lactic acid bacteria and a major electron acceptor for all lactic acid bacteria. Alternative electron acceptors (A) can be reduced intracellularly or extracellularly. The electrons are directed towards the acceptors through various dehydrogenases $(\mathrm{DH})$ possibly via menaquinones or disulphides.

A: electron acceptor; RA: reduced form of A (examples of As and corresponding RAs are given in Table 1); $D H$ : dehydrogenase; GIpD: glycerol-3-phosphate dehydrogenase; G3P: glycerol-3-phosphate; DHAP:

dihydroxyacetonephosphate; $\mathrm{MK}$ : menaquinone; $\mathrm{MKH}_{2}$ : menaquinol; NAD: nicotinamide adenine dinucleotide; $\mathrm{NADH}$ : reduced form of nicotinamide adenine dinucleotide; NoxAB: NADH dehydrogenase AB; NoxE: NADH oxidase E; CytBC: cytochrome bc; $\mathrm{LDH}$ : lactate dehydrogenase; TR: thioredoxin reductase; $\mathrm{TS}_{2}$ : thioredoxin oxidized form; $\mathrm{T}(\mathrm{SH})_{2}$ : thioredoxin reduced form; GR: glutathione reductase; GSH: glutathione; (GS) $2_{2}$ : oxidized gluthation; ESP: exo facial thiol containing protein.

Highlights

- pathways of redox reactions distinguish cultures for food fermentations

- range of electron acceptors in food matrices differ between food and types of cultures

- redox engineering of cultures for food fermentations is underexploited 


\section{Outside (food matrix)}

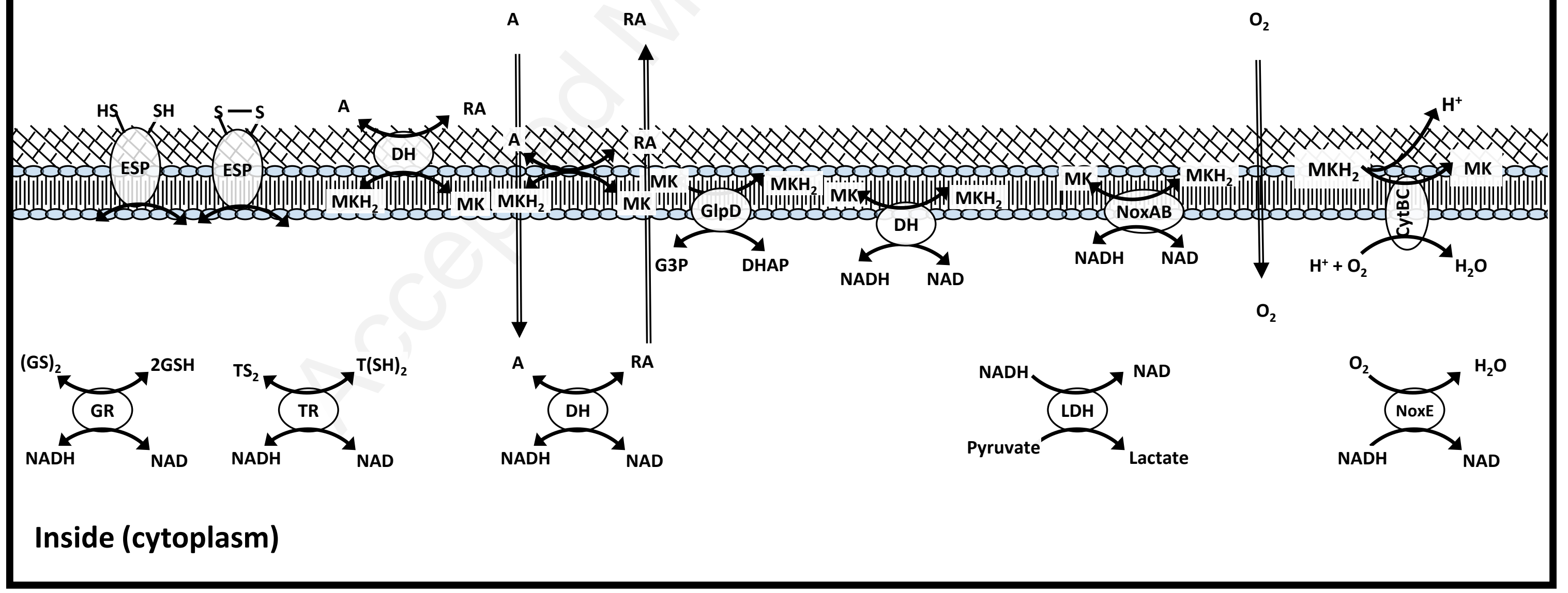

